\title{
Manchas hipomelanocíticas associadas à epilepsia: alerta ao diagnóstico de esclerose tuberosa
}

\author{
Hypopigmented macules associated to seizures must raise \\ avareness for the possibility of the diagnosis \\ of tuberous sclerosis
}

\author{
Mariana C. Moreira1, Caio R. D. C. Quaio', Israel Gomy², \\ Débora R. Bertola², Chong Ae Kim ${ }^{3}$
}

Moreira MC, Quaio CRDC, Gomy I, Bertola DR, Kim CA. Manchas hipomelanocíticas associadas à epilepsia: alerta ao diagnóstico de esclerose tuberosa/ Hypomelanotic spots associated with epilepsy: alert to the diagnosis of tuberous sclerosis. Rev Med (São Paulo). 2012 abr.-jun.;91(2):117-9.

$\Delta$ esclerose tuberosa (ET) é uma doença multissistêmica de herança autossômica dominante caracterizada pelo desenvolvimento de hamartomas em diversos órgãos, com incidência estimada em 1:10.000 a 1:6.000 nascidos vivos. Sua ocorrência relaciona-se a mutações com perda de função nos genes TSC1 e TSC2, cujos produtos proteicos (respectivamente hamartina e tuberina) formam um heterodímero com importante função na supressão tumoral e no controle do ciclo celular ${ }^{1,2}$.

Clinicamente a ET manifesta-se com ampla constelação de sinais e sintomas, sendo frequentes crises convulsivas e deficiência intelectual de grau variável. O diagnóstico definitivo é estabelecido clinicamente pela presença de dois critérios maiores e um menor ou um maior e dois menores, segundo consenso internacional. ${ }^{3} \mathrm{~A}$ presença de manchas hipomelanocíticas na infância, principalmente associada a epilepsia, é sinal de alerta á possibilidade do diagnóstico da ET e é considerada critério maior para diagnóstico.
A literatura brasileira é escassa de dados clínicos e epidemiológicos sobre a relevância da ET na população nacional, bem como sobre a variabilidade fenotípica nessa população.

Realizamos, em nosso serviço, detalhamento sobre as características fenotípicas mais relevantes de 15 pacientes com diagnóstico de ET. Esperase contribuir para a melhor caracterização das manifestações precoces dessa doença na população brasileira.

Um estudo retrospectivo foi realizado em nossa instituição com todos os pacientes que preenchiam critérios clínicos para diagnóstico definitivo para ET. No total, 15 pacientes foram selecionados, 11 do sexo masculino e 4 do sexo feminino. A idade variou de 6 meses a 20 anos (média de 10,3 anos) e a idade ao diagnóstico de 53 dias aos 19 anos (média de 7,9 anos). Em um terço dos casos encontramos agregação familiar.

Os principais achados clínicos estão listados na Tabela 1.

\footnotetext{
1. Médico Residente de Genética Médica do Hospital das Clínicas da Faculdade de Medicina da Universidade de São Paulo, São Paulo, SP, Brasil.

2. Médico assistente da Unidade de Genética do Instituto da Criança do Hospital das Clínicas da Faculdade de Medicina da Universidade de São Paulo, São Paulo, SP, Brasil.

3. Livre Docente e Chefe da Unidade de Genética do Instituto da Criança do Hospital das Clínicas da Faculdade de Medicina da Universidade de São Paulo, São Paulo, SP, Brasil.

Endereço para correspondência: Mariana C. Moreira. Av. Dr. Enéas Carvalho de Aguiar, 647. São Paulo, SP, Brasil. CEP: $05403-000$. e-mail: mariridcm@yahoo.com.br
} 
Tabela 1. Achados clínicos na Esclerose Tuberosa e comparação com literatura

\begin{tabular}{|c|c|c|}
\hline Achados clínicos & Presente estudo & Revisão de literatura ${ }^{4}$ \\
\hline Casos familiais & $33 \%$ & $33 \%$ \\
\hline \multicolumn{3}{|l|}{ Critérios maiores } \\
\hline Máculas hipomelonocíticas (3 ou mais) & $100 \%$ & $87-100 \%$ \\
\hline Túberes corticais & $100 \%$ & $70 \%$ \\
\hline Nódulos subependimários & $53 \%$ & $90 \%$ \\
\hline Rabdomioma cardíaco & $53 \%$ & $47-67 \%$ \\
\hline Angiofibromas & $33 \%$ & $47-90 \%$ \\
\hline Angiomiolipomas renais & $20 \%$ & $70 \%$ \\
\hline Fibroma periungueal & $7 \%$ & $17-87 \%$ \\
\hline Mancha de Shagreen & $7 \%$ & $20-80 \%$ \\
\hline Linfangiomiomatoses pulmonares & $0 \%$ & $6 \%$ \\
\hline \multicolumn{3}{|l|}{ Critérios menores } \\
\hline Hamartomas não renais & $47 \%$ & $13 \%$ \\
\hline Manchas retinianas & $13 \%$ & Maior que $75 \%$ \\
\hline Cistos renais & $7 \%$ & $20-30 \%$ \\
\hline Pólipo retal hamartomatoso & $7 \%$ & $80 \%{ }^{5}$ \\
\hline \multicolumn{3}{|l|}{ Outros achados relevantes } \\
\hline Crises convulsivas & $60 \%$ & $80 \%$ \\
\hline Atraso de desenvolvimento neuropsicomotor & $7 \%$ & Maior que $50 \%$ \\
\hline Arritmia cardíaca & $7 \%$ & - \\
\hline
\end{tabular}

Ao analisar os principais achados de nossa coorte de 15 pacientes que preencheram critérios diagnósticos clínicos de ET, observamos que a amostra foi composta principalmente de crianças e um terço dos pacientes eram casos familiares.

Máculas hipomelanocíticas, estavam presentes em $100 \%$ dos pacientes analisados. Essas em geral começam a parecer até os 5 anos de idade. A maioria dos pacientes (60\%) teve ao menos um episódio de crise convulsiva. As manifestações clínicas iniciais mais comuns da ET são espasmos infantis ou crises convulsivas precoces na infância, sendo importante diagnóstico diferencial da síndrome de West ${ }^{1,2}$. O aumento de movimentos fetais pode ser um indicativo precoce de convulsões intra-uterinas.

A presença de máculas hipomelanocíticas em crianças com crises convulsivas ou com alterações no exame neurológico deve suscitar a suspeita clínica do médico assistente para a possibilidade diagnóstica de ET. Sendo assim, estudo tomográfico ou ressonância magnética de encéfalo deve ser solicitado para complementar investigação, já que túberes corticais foram também encontrados em todos os nossos pacientes.

A tríade composta por rabdomioma cardíaco, espasmos ou crises convulsivas de início precoce e arritmia cardíaca foram as manifestações clínicas mais importantes observadas logo após o nascimento e, quando presentes, devem ser reconhecidas por neonatologistas como sinais sugestivos de ET. Rabdomioma cardíaco esteve presente em metade dos nossos pacientes e regrediu espontaneamente antes dos três anos de idade em todos. Esse tumor cardíaco pode ser diagnosticado precocemente na ultrassonografia fetal e sua regressão espontânea é comumente relatada na literatura ${ }^{1,2,3}$.

Foi observada taquiarritmia fetal em um paciente do sexo feminino que necessitou do uso de amiodarona pela mãe durante a gestação até o último trimestre. A taquiarritmia resolveu espontaneamente durante os primeiros meses após o nascimento, sem recidiva posterior.

Outros achados associados tais como nódulos subependimários, hamartomas hepáticos, angiomiolipomas renais, fibromas periungueais, manchas de Shagreen, linfangiomiomatoses pulmonares, manchas retinianas, astrocitoma de células gigantes e pólipos retais hamartomatosos tiveram menor frequência em nosso estudo quando comparado à literatura. Isso pode ser explicado pelo fato de a maioria dessas lesões se manifestarem na 
infância tardia ou na vida adulta, enquanto nossa coorte é composta basicamente por população pediátrica ${ }^{1-5}$.

Observaram-se múltiplos cistos renais em um paciente, achado incomum na literatura. É tentador especular que uma microdeleção envolvendo os genes TSC2 e PKD1, que são contíguos, poderia explicar a associação entre ET e doença renal policística de herança autossômica dominante. Essa associação determinaria um pior prognóstico com insuficiência renal na vida adulta. Em 2-3\% dos pacientes com ET, grandes deleções no TSC2 podem afetar o gene adjacente da doença renal policística tipo $1(P K D 1)^{1-3}$.

$\mathrm{Na}$ literatura nacional, há alguns relatos de casos isolados abordando o tema ET. Yacubian et al. ${ }^{6}$ publicaram a única casuística relevante a avaliar principalmente o comprometimento cognitivo e epilepsias em 15 pacientes jovens. Achados de comprometimento cognitivo e epilepsia foram comuns e afetaram $87 \%$ da amostra, número maior

\section{REFERÊNCIAS}

1 Crino PB, Nathanson KL, Henske EP. The tuberous sclerosis complex. New Eng J Med. 355: 1345-1356, 2006.

2 Curatolo P, Bombardieri R, Joswiak S. Tuberous Sclerosis. Lancet. 2008;372:657-68.

3 Roach ES, Gomez MR, Northrup H. Tuberous sclerosis complex consensus conference: revised clinical diagnostic criteria. J Child Neurol. 1998;13(12):6248.

4 Northrup H, Au KS (Updated May 7, 2009). Tuberous Sclerosis Complex. In: GeneReviews at GeneTests: do que encontrado no presente estudo. No entanto, tumor cardíaco fora achado em $7 \%$, enquanto no nosso estudo essa frequência foi de $50 \%$. Essas discrepâncias podem ser explicadas pelo fato de ambas as casuísticas serem pequenas, apesar de representarem as maiores séries de caso nacionais.

A heterogeneidade fenotípica na ET mostra-se um desafio ao médico em estabelecer um diagnóstico precoce. Assim, devemos estar atentos às formas mais comuns de apresentação da ET, como manchas hipomelanocíticas associadas à epilepsia, para que se institua abordagem multidisciplinar adequada que garanta qualidade no manejo clínico. Lembramos que a ET trata-se de doença genética de herança autossômica dominante com risco de recorrência de $50 \%$ se um dos genitores for afetado. Assim, o exame clínico dos genitores e complementação com estudo tomográfico, mesmo na ausência de manchas cutâneas, é mandatório para o adequado aconselhamento genético.
Medical Genetics Information Resource (database online). Seattle: University of Washington; 1997-2011 [cited 2011 June 21]. Available from: http://www. genetests.org.

5 Gould SR. Hamartomatous rectal polyps are common in tuberous sclerosis. Ann N Y Acad Sci. 1991;615:7180.

6 Yacubian EM, Assumpçäo-Júnior FB, Duarte JC, Colarille LC, Marcucci M, Madruga MF, Lauandos TC, Ramos TC, Funari AS, Cruz LM, Sprovieri MH. Tuberous sclerosis: a multidisciplinary study of 15 cases. Arq Neuropsiquiatr. 1983;41(2):163-70. 